\title{
EDUCAÇÃO FÍSICA ESCOLAR ALIADA A PREVENÇÃO DA OBESIDADE EM PESSOAS COM SÍNDROME DE DOWN
}

\author{
Antonio Carlos Mazzerocchi Rodrigues ${ }^{1}$ \\ Geverson Tobias Böhm ${ }^{2}$ \\ Sandra Ines Horn Bohm ${ }^{2}$ \\ Nádia Ligianara D. Nyari ${ }^{3}$ \\ Moacir Juliani ${ }^{3}$
}

\begin{abstract}
Resumo: A síndrome de Down (SD), conhecida como trissomia do cromossomo 21 é uma das principais causas de deficiência intelectual, dentre elas, o retardo mental e de crescimento, e desenvolvimento de obesidade que pode perdurar até a vida adulta. Uma alimentação inadequada colabora substancialmente para os riscos cardiovasculares, decorrentes de hábitos alimentares monótonos e inadequados com acréscimo de alimentos industrializados ricos em sódio, gorduras saturadas e açúcares. Pouco se conhece sobre as reais necessidades nutricionais específicas desses indivíduos. Diante do exposto e considerando o número reduzido de pesquisas que investiguem esse segmento aliada a prática de atividade física em pessoas com síndrome de Down, justificaram a realização desse estudo, cujo objetivo de contribuir, identificar e analisar a importância da Disciplina de Educação Física na Idade Escolar na prevenção da Obesidade em pessoas com Síndrome de Down. Nesse sentido buscou conhecer as especificidades da Síndrome de Down em relação ao metabolismo, observando a ocorrência de obesidade e identificando as causas da obesidade nos estudantes. Para tanto o método de estudo empregue foi de abordagem indutiva e qualitativa. $O$ grupo de pesquisa foi composto de 01 nutricionista, 08 professores de Educação Física e 10 estudantes com Síndrome de Down, através de 03 instrumentos de pesquisa, entrevista, questionário misto e verificação do índice de Massa Corporal (IMC). A partir das informações obtidas foi possível identificar a necessidade de novos estudos a fim de contribuir e melhorar a alimentação e os hábitos alimentares de pessoas com Síndrome de Down.
\end{abstract}

Palavras chave: Educação; Sobrepeso; Saúde; Qualidade de Vida; Portadores de Síndrome de Down.

\footnotetext{
${ }^{1}$ Discente do Curso de Licenciatura em Educação Física da Faculdade La Salle de Lucas Rio Verde, MT. ${ }^{2}$ Docente Mestre da Faculdade La Salle de Lucas Rio Verde, MT. E-mail sandra@faculdadelasalle.edu.br; geverson.bohm@faculdadelasalle.edu.br

${ }^{3}$ Docente Doutor (a) da Faculdade La Salle de Lucas Rio Verde, MT. E-mail nadia.nyari@faculdadelasalle.edu.br; moacir.juliani@faculdadelasalle.edu.br
} 


\section{SCHOOL PHYSICAL EDUCATION ALLIES THE PREVENTION OF OBESITY IN PERSONS WITH DOWN SYNDROME}

Abstract: Down syndrome (SD), known as trisomy 21 is one of the main causes of intellectual disability, among them, mental retardation and growth, and development of obesity that can last until adult life. Inadequate nutrition contributes substantially to cardiovascular risks, resulting monotonous and inadequate food products with the addition of industrialized foods rich in sodium, saturated fats and sugars. Little is known about the actual specific nutritional needs of these individuals. Considering the above and considering the small number of research investigating this segment allied to the practice of physical activity in people with Down syndrome, justified the accomplishment of this study, whose objective is to contribute, identify and analyze the importance of the Physical Education Discipline in the Age School in the prevention of Obesity in people with Down Syndrome. In this sense, he sought to know the specificities of Down Syndrome in relation to metabolism, observing the occurrence of obesity and identifying the causes of obesity in students. For that, the method of study used was of an inductive and qualitative approach. The research group was composed of 01 nutritionist, 08 Physical Education teachers and 10 students with Down Syndrome, through 03 research instruments, interview, mixed questionnaire and verification of Body Mass Index (BMI). From the information obtained, it was possible to identify the need for new studies to contribute to and improve the diet and eating habits of people with Down Syndrome.

Keywords: Educação; Sobrepeso; Saúde; Qualidade de Vida; Portadores de Síndrome de Down.

\section{INTRODUÇÃO}

A Educação Física vem trazendo grandes efeitos para o ser humano, principalmente no que se refere à busca incessante pela qualidade de vida de todos (WILLIAMS e BENDELOW, 1998). O corpo na modernidade é convocado pela mídia e pelas relações de consumo para vender estilos de vida saudáveis, como nas propagandas da eterna jovialidade, a erotização do corpo e o sexo desenfreado que produzem a compulsão e a "escravidão" da atividade física (CAMPANELLI et al., 2018).

A Educação Física escolar tem atualmente se preocupado com a qualidade de vida e inclusão de todos em suas aulas práticas. Recentemente desenvolveu-se a Educação Física adaptada para que os benefícios das aulas sejam estendidos a todos, principalmente quaisquer pessoas portadoras de transtornos, sejam eles psicológicos ou físicos, que impeçam que essas pessoas participem ativamente de uma aula comum da disciplina, como os portadores de deficiências mentais, visuais, auditivas, físicas, com múltiplas deficiências, superdotados, com

Revista Extensão em Foco, nº 19, Jul./ Dez. (2019), p. 11 - 32. 
Síndromes neurológicas, psiquiátricas e psicológicas, e ainda pessoas com dificuldades de aprendizagem (CARVALHO, 2008).

No desenvolvimento das atividades na Escola de Educação Especial percebeu-se que os estudantes com Síndrome de Down apresentam variados graus de obesidade, constando - se assim que os mesmos participam das aulas de Educação Física. Todavia a partir das considerações apresentadas anteriormente o problema que move a nossa investigação é restrita como a Educação Física escolar pode prevenir a obesidade das pessoas com a Síndrome de Down?

Nesse sentido é possível evitar e prevenir que os estudantes com Síndrome de Down possam manter seus índices de saúde saudáveis, evitando assim o sobrepeso e a obesidade, hipertensão arterial e a diabetes, além de possíveis patologias. Portanto sabe -se que as aulas de Educação Física podem ir mais além, principalmente devido ao contato docente e discente, possibilitando um papel motivador, com a adoção de práticas de atividade física saudáveis, inserindo esses ambientes escolares e na sociedade, aprimorando seus benefícios como a qualidade de vida e a manutenção da saúde física e mental.

A recente percepção e a presença dos estudantes com Síndromes de Down nos espaços sociais, possibilitou a quebras de paradigmas, principalmente em decorrência ao temor da rejeição e de atitudes preconceituosas por parte das outras pessoas. Contudo para Sassaki (2002) considera uma proposta de segregação por de trás da pretensa inclusão, quando na verdade a classe especial serve de locus no qual as crianças especiais são postas a fim de evitar o convívio (contaminação) com os demais alunos.

Atualmente os meios de comunicação social, como a mídia veiculam constantemente a ideia do corpo perfeito através da proliferação de padrões da perfeição ditados pela moda. A partir destes padrões percebe - se que as pessoas normalmente não encontram em conformidade com estes padrões que a mídia apresenta, passam na maioria das vezes por situações de exclusão. Sendo assim entende-se que as pessoas com Síndrome de Down desta forma são excluídas duplamente, contudo o objetivo desse estudo visa apresentar a real importância da disciplina de Educação Física ministrada para os alunos com necessidades especiais, contribuindo assim como material de possíveis pesquisas futuras para acadêmicos, professores e familiares nesse segmento.

Revista Extensão em Foco, nº 19, Jul./ Dez. (2019), p. 11 - 32. 


\section{REVISÃO BIBLIOGRÁFICA}

\section{Educação Física}

De acordo com estudiosos da área, Betti (1991), Darido (2003), Soares (1992) entre outros, a Educação Física escolar passa por transformações em relação aos conteúdos que devem ser desenvolvidos nos espaços escolares nos diferentes níveis de ensino. Sabemos que, desde a sua implantação no Brasil até os dias atuais, várias convergências pedagógicas norteiam a sua prática nas escolas, bem como seus princípios.

A escola oferece possibilidade aos estudantes de desenvolverem a educação seja ela física, cognitiva, psicológica, emocional e com isso a Educação Física escolar pode contribuir para os estudantes se desenvolvam em diferentes aspectos, e todos têm o mesmo direito de vivenciar cada atividade com motivação e uma alta estima de querer participar, ter prazer pelas aulas de Educação Física. Entender a respeito de construir momentos de aprendizagem significativa é da responsabilidade do educador.

Conforme João Batista Freire (2009) é inquestionável o benefício da atividade física no desenvolvimento de uma criança, sendo possível verificar o real benefício dentro da escola e nas aulas de Educação Física escolar. Podemos perceber que a Educação Física traz vários benefícios na escola isso acontece quando o profissional tem um entendimento de cada atividade que é desenvolvida com os seus alunos é muito mais que brincadeira, pois envolve movimentos onde são construídas aprendizagens para os estudantes.

De acordo com Freire (1994) corpo e mentes devem ser entendidos como componentes que integram um único organismo. Ambos necessitam ter assento na escola. Portanto, a Educação Física deve ser entendida como linguagem integrada com outros com as outras áreas e permite refletir na assimilação do conhecimento da cultura corporal de movimento.

E já em seus estudos, Daólio (1995) afirma que a natureza humana é um ser cultural, ao mesmo tempo fruto e agente da cultura. Nesta concepção, o profissional da disciplina Educação Física escolar tem uma função relevante a desempenhar, pois ocupa uma posição excepcional para dar respaldo de cunho educacional e social junto aos seus alunos. É um dos propósitos a ser obtido por todos aqueles que confiam e começam a perceber a estimação de se reaver o sentido do ser humano e do corpo.

De acordo com os Parâmetros Curriculares Nacionais (1998), a Educação Física deve ser entendia como uma área de conhecimentos da cultura corporal de movimento e a Educação Revista Extensão em Foco, nº 19, Jul./ Dez. (2019), p. 11 - 32. 
Física escolar como uma disciplina que introduz e integra o aluno na cultura corporal de movimento, formando o cidadão que vai produzi-la, reproduzi-la e transformá-la.

Portanto é notável perceber que a Educação Física Escolar deva dar propriedades a todos os alunos para que desenvolvam suas potencialidades, de forma popular, visando seu aperfeiçoamento como seres humanos, em todas as suas extensões. É com esses valores e princípio de inclusão, que aponta para uma perspectiva metodológica de educação e aprendizagem que busca o desenvolver-se da autonomia, a colaboração, a participação social e a afirmação de valores (NEIRA, 2003).

Com visão aos pensamentos do autor, partindo da suposição de que cada aluno é um ser especial e com um tempo favorável para aprender e que o mesmo se encontra em semelhança aos demais, em nível diferente, referente ao procedimento de conquista e constituição de seu conhecimento, é importante que o educasse seja instigado e estimulado a adotar a ocasião de sujeito dessa construção.

\section{Inclusão da Educação Física Escolar nas Aulas}

Segundo Goffredo (1998), o termo educação inclusiva, começando a ser empregado partir da Conferência Mundial de Educação Para Todos (1990) e da Declaração Salamanca (1994), inspirada nos princípios de integração e no reconhecimento da necessidade de ação para conseguir "escolas para todos". Glat (1998) abordou questões relacionadas à inserção do deficiente na sociedade, na visão de inserir o cidadão na sociedade e no ambiente escolar, de mostra que somos inclusos ou excluídos dos ambientes seja ele escolar ou sociedade, independente de quem somos ou deixamos de ser somos todos diferentes (FIGUEIRA, 2017).

Nas escolas, "pressupõe, conceitualmente, que todos, sem exceção, devem participar da vida acadêmica, em escolas ditas comuns e nas classes ditas regulares onde deve ser desenvolvido o trabalho pedagógico que sirva a todos, indiscriminadamente" (EDLER CARVALHO, 1998).

Com pensamento do autor podemos constatar a visão de que o ser humano tem que ser incluso dentro do contexto escolar sem exceção de cor raça, e de alguma conformidade e dentro da inclusão nas aulas de Educação Física não seja diferente. A Educação Física na escola se estabelece em uma grande área de ajustamento ao permitir, a participação de crianças e jovens em agilidades físicas apropriadas às suas probabilidades, harmonizando que sejam valorizados e se integrem num mesmo mundo.

Revista Extensão em Foco, nº 19, Jul./ Dez. (2019), p. 11 - 32. 
Um ensino de libertação de falsas ilusões, de falsos interesses e desejos, criados e construídos nos alunos pela visão de mundo que apresentam a partir do conhecimento. $\mathrm{O}$ ensino escolar necessita desta forma, basear-se numa concepção crítica (DARIDO, 2004). Com pensamentos de que as aulas de Educação Física escolar podem incluir e não excluir, e sem ilusão de que realmente está sendo incluso. Educação crítica, onde aluno tem o direito e terá condições de suspender as estruturas autoritárias, promovendo a emancipação, permeada pelo uso da linguagem.

Por sua vez, a linguagem, segundo a autora, é um importante agente na comunicação e propicia uma forma de expressão de entendimento do mundo social, na tomada de decisões, ao formular interesses e preferências "e agir de acordo com o grupo ao que está inserido e do trabalho no esforço de conhecer, desenvolver e apropriar-se de cultura" (DARIDO, 2004). Com essas palavras vemos que a escola ela prepara o aluno para ser um cidadão com valores e conceitos éticos dentro da sociedade, percebemos que a escola ela tem o dever de incluir o aluno na sociedade e não exclui.

\section{Síndrome de Down - Especificada}

Basicamente a Síndrome de Down significa que seu bebê tem um cromossomo extra em cada uma dos seus milhões de célula. Em vez de 46, ele tem 47 cromossomos. Anualmente nascem mais de 6 mil bebês com Síndrome de Down nos Estados Unidos, e alguns milhares mais em outros países. Essa Síndrome ocorre igualmente em meninos e meninas. É um dos defeitos congênitos mais comuns, apresentando-se em todas as raças, grupos étnicos, classes socioeconômicas e nacionalidades. Pode acontecer a qualquer pessoa (MRECH, 1999).

Segundo Schwartzman (1999), a Síndrome de Down é marcada por muitas alterações associadas, que são observados em muitos casos. As principais alterações orgânicas, que acompanham a Síndrome são: cardiopatias prega palmar única, baixa estatura, atresia duodenal, comprimento reduzido do fêmur e úmero, bexiga pequena e hiperecogênica, ventriculomegalia cerebral, hidronefrose e dismorfismo da face e ombros.

Outras alterações como braquicefalia, fissuras palpebrais, hipoplasia da região mediana da face, diâmetro fronto-occipital reduzido, pescoço curto, língua protusa e hipotônica e distância aumentada entre o primeiro, o segundo dedo dos pés, crânio achatado, mais largo e comprido; narinas normalmente arrebitadas por falta de desenvolvimentos dos ossos nasais;

Revista Extensão em Foco, nº 19, Jul./ Dez. (2019), p. 11 - 32. 
quinto dedo da mão muito curto curvado para dentro e formado com apenas uma articulação; mãos curtas; ouvido simplificado; lóbulo auricular aderente e coração anormal.

Quanto às alterações fisiológicas podemos observar nos primeiros dias de vida uma grande sonolência, dificuldade de despertar, dificuldade de realizar sucção e deglutição, porém estas alterações vão se atenuando ao longo do tempo, à medida que a criança fica mais velha e se torna mais alerta. A criança Down normalmente apresenta grande hipotonia e segundo Hoyer e Limbrock, citado por Schwartzman (1999), o treino muscular precoce da musculatura poderá diminuir a hipotonia. A hipotonia costuma ir se atenuando à medida que a criança fica mais velha e pode haver algum aumento na ativação muscular através da estimulação tátil. (LOTT apud SCHWARTZMAN, 1999).

Alterações fisiológicas também se manifestam através do retardo no desaparecimento de alguns reflexos como o de preensão, de marcha e de Moro. Este atraso no desaparecimento destes reflexos é patológico e resulta no atraso das aquisições motoras e cognitivas deste período, já que muitas atividades dependem da desta inibição reflexa para se desenvolverem como o reflexo de moro, que é substituído pela marcha voluntária.

\section{Síndrome de Down x Obesidade}

A Síndrome de Down (SD) é uma doença congênita que foi descrita pela primeira vez em 1866 por Langdon Down. Este distúrbio genético acarreta alterações físicas e mentais e pode ser explicado por um desequilíbrio na constituição do número de cromossomos, no caso, a presença do cromossomo 21 extra, caracterizando a trissomia 21 (SCHWARTZMAN et al., 1999).

Esta Síndrome pode ser causada por três tipos de alterações cromossômicas: trissomia 21 livre (96\%), translocação (3\%) e mosaicismo (1\%) (PUESCHEL, 1999). A obesidade é uma patologia que vem aumentando significativamente nas últimas décadas, entretanto as pesquisas sobre a mesma em portadores com Síndrome de Down (SD), ainda são escassas (OTTO e FROTA-PESSOA, 2004; SILVA et al., 2017). Esta Síndrome é constituída por um grupo específico de indivíduos onde se observam prevalências de excesso de peso e obesidade superiores em relação às populações normais.

Podemos dizer que a obesidade existe quando a parcela de tecido adiposo representa mais de $20 \%$ do peso corporal total no homem e mais de $25 \%$ na mulher aproximadamente (ABESSO, 2010). A ingestão alimentar é determinada essencialmente pelos centros Revista Extensão em Foco, nº 19, Jul./ Dez. (2019), p. 11 - 32. 
hipotalâmicos (hormônios hipotalâmicos atuam no controle das células glandulares que secretam os hormônios epifisários). Hormônios hipotalâmicos atuam sobre as sensações de fome e saciedade (JUNQUEIRA e CARNEIRO, 1995).

Segundo World Health Organization, (PINHEIRO et al 2004), em estudos de populações, o índice de Massa Corporal (IMC) (definido pelo peso em kg dividido pela altura em metros quadrados) torna-se medida útil para avaliar o excesso de gordura corporal, sendo consensual admitir que, independentemente de sexo e idade, adultos com IMC igual ou superior a 30kg/m2 devem ser classificados como obesos (CRONK et al apud ALMEIDA 2006).

\section{Síndrome de Down e as Aulas de Educação Física}

Nesta direção Alves (2007) diz que cabe, portanto ao professor ser investigador, ou seja, aquele que ouve, vê e procura compreender o potencial de cada criança com quem trabalha, possibilitando a não limitação e a possibilidade de desenvolvimento intelectual dos estudantes. De acordo com o autor esse realmente é o dever do profissional, da área da Educação Física para que tenha um desempenho com cada indivíduo, em suas aulas.

Segundo Pueschel (2005), a Síndrome de Down é um distúrbio cromossômico e uma causa importante da deficiência intelectual. Para o autor, tais impedimentos não tornam os indivíduos incapazes de aprender, por isso compreender o que a Síndrome de Down significa é um passo importante para a sua inclusão na escola (LOPES DE CARVALHO e FERREIRA DE ARAÚJO, 2018).

Sassaki (2003) aponta que a educação inclusiva é o processo que ocorre em qualquer escola preparada para propiciar um ensino de qualidade aos seus alunos, independentemente de seus atributos pessoais, de seu intelecto, seus estilos de aprendizagem e necessidades. Enquanto Mantoan (2003), para que a inclusão ocorra, a escola deve levar em consideração que o tempo de construção de uma competência varia de aluno para aluno e que sua evolução é percebida por meio da mobilização e da aplicação do que este aprendeu ou já sabia para chegar às soluções pretendidas.

Como salientam a PFDC (2003), os professores devem ter em mente que alguns alunos podem não chegar a aprender exatamente o que os demais aprenderam, devido ao déficit intelectual, mas mesmo assim têm o direito de serem avaliados por aquilo que conseguiram desenvolver ao longo de suas atividades. Paniagua (2004) expressa ser fundamental que ocorra uma comunicação permanente entre a família e a escola, pois a resposta a muitas necessidades Revista Extensão em Foco, no 19, Jul./ Dez. (2019), p. 11 - 32. 
educacionais especiais supõe um esforço coordenado entre ambas. Podemos perceber que a inclusão depende não somente da escola e sim da família, para que acontece a inclusão e não exclusão no ambiente escolar, e fora da escola e sim dentro da sociedade (CAMPANELLI et al., 2018).

Para que a escola atenda às especificidades de seus alunos, tendo eles ou não alguma necessidade educacional especial, ela precisa ser reestruturada. Dessa forma, alguns autores (TORRES-GONZÁLEZ, 2002; MANTOAN, 2003; LIMA, 2006; MENDES, 2006; SILVA, 2018) enfatizam a importância da diversidade, ressaltando a necessidade da reorganização da cultura escolar para que sejam oferecidas aos alunos respostas democráticas às suas necessidades e habilidades.

A educação inclusiva implica mudanças de paradigmas. É necessário pensarmos que todos os alunos são diferentes e não somente aqueles que apresentam algum tipo de deficiência (BEYER, 2005; da SILVA et al., 2018; DIAS, 2018). As adequações curriculares, que ocorrem conforme as probabilidades de aprendizagem de cada aluno.

\section{METODOLOGIA}

O campo de pesquisa deste projeto de investigação está situado no campo das ciências sociais de modo que este trabalho caracterizando a pesquisa qualitativa que segundo o autor (cita o autor, ano e página) pode ser assim conceituada. Silva e Menezes (2001) corroboram afirmando que pesquisas com abordagens qualitativas estabelecem vínculos entre o mundo objetivo e a subjetividade do sujeito não permitindo que os resultados sejam traduzidos através de números.

Esta pesquisa é o tipo descritiva pois apresenta e descreve a realidade de um grupo de pessoas, no caso os estudantes com Síndrome de Down com um método indutivo, tendo como instrumentos de pesquisa questionário, pois partiu da realidade com finalidade de entender possíveis contextualizações. A mostra foi constituída de 08 professores de diferentes escolas e áreas, com experiência em docência, nutricionistas e 10 estudantes com necessidades educativas especiais, sendo 06 do sexo masculino e 04 do sexo feminino.

\section{RESULTADOS E DISCUSSÕES}

Revista Extensão em Foco, nº 19, Jul./ Dez. (2019), p. 11 - 32. 


\section{Caracterização dos Alunos e Professores}

As informações a seguir estão relacionadas com o perfil dos professores de Educação Física apresentando gênero, idade, grau de escolaridade e tempo de atuação na escola (Figura 1a) e a faixa etária (Figura 1b).

Figura 1 - Gênero (a) e Faixa etária (b) dos Professores de Educação Física Escolar.

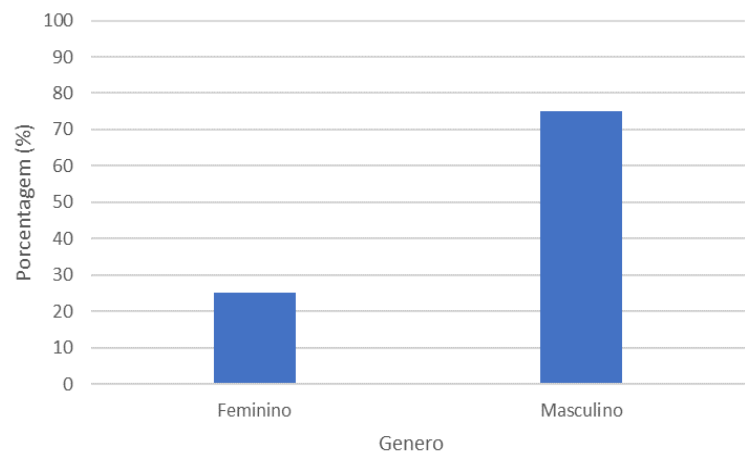

(a)

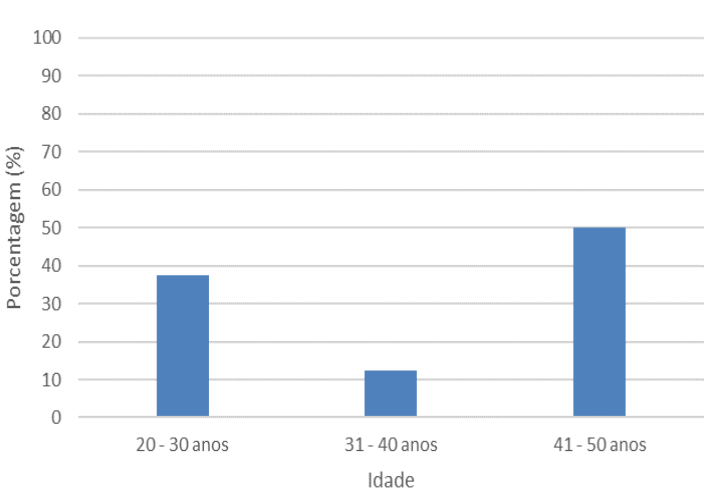

(b)

De acordo com os dados da pesquisa, como mostra o gráfico a seguir, $75 \%$ dos professores entrevistados é do sexo masculino (Figura 1a). De acordo com estes dados percebese que no universo dos professores de Educação Física Escolar pesquisado ocorreu predominância do gênero masculino no atendimento dos estudantes com Síndrome de Down. A maioria dos professores de Educação Física escolar tem entre 40 e 50 anos o que equivale a $50 \%$ dos respondentes (Figura 1b). Com relação ao grau de escolaridade (Figura 2 a) e o tempo (Figura 2b) de atuação no magistério dos professores de Educação Física escolar. A Rede de Ensino na qual realizam o exercício da docência (Figura 2c).

Verifica-se que todos os professores de Educação Física escolar pesquisados apresentam a graduação em Educação Física Licenciatura (Formação Inicial) e 50\% destes possui Especialização (Figura 2a). Em relação ao tempo de exercício no magistério, constatando que $50 \%$ dos professores têm entre 06 e 10 anos de atuação (Figura 2b).

Figura 2 - Grau de Escolaridade (a), Tempo de Atuação (b) em Magistério dos professores de Educação Física Escolar e a Rede de Ensino (c) na qual realizam o exercício da docência.

Revista Extensão em Foco, no 19, Jul./ Dez. (2019), p. 11 - 32. 


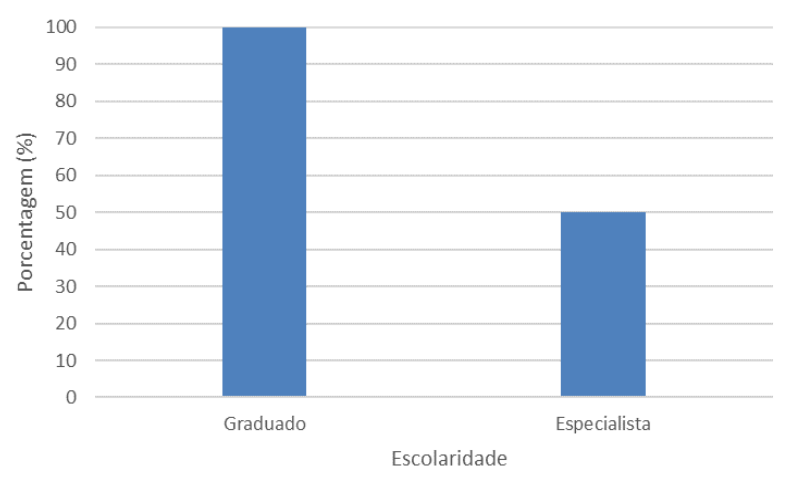

(a)

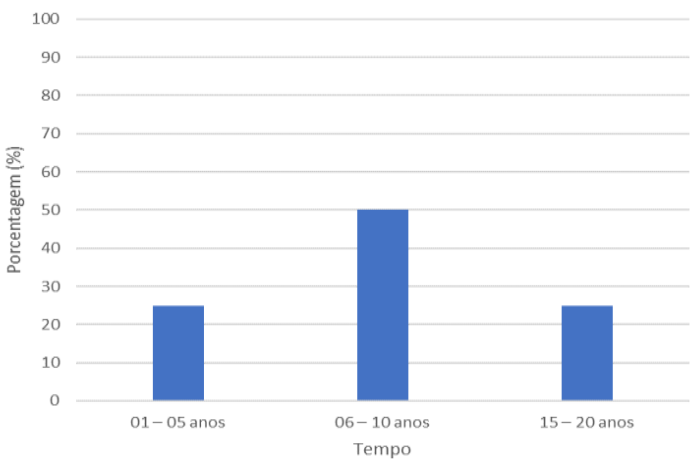

(b)

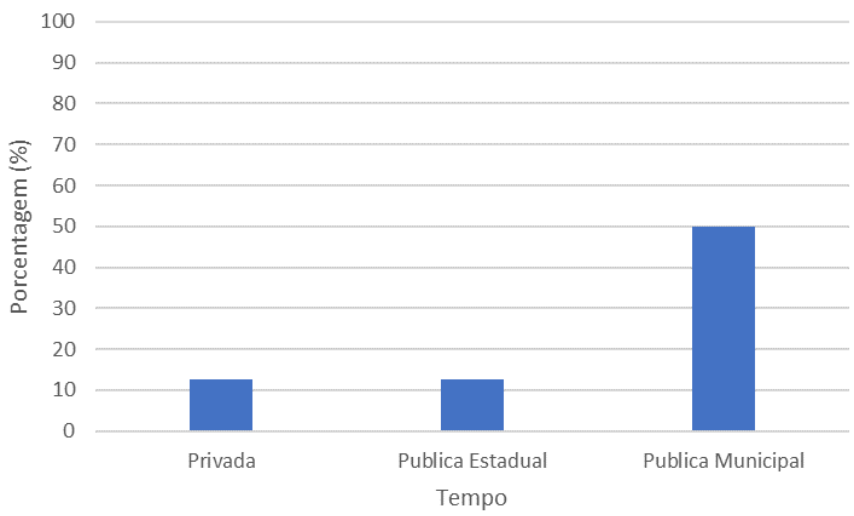

(c)

A respeito da rede de ensino em relação ao tempo de exercício no magistério (Figura 2 c) em que cada professor atua, verificou-se que 50\% dos entrevistados trabalham na rede municipal.

\section{Percepções dos Estudantes de Pesquisa - Professores de Educação Física Escolar}

Com relação as turmas em que o professor ministrou aulas de Educação Física, com alunos com necessidades especiais (Figura 3a) qual o tipo necessidade Especial (Figura 3b).

Todos afirmaram já ter tido experiência de exercício docente com estudantes que apresentavam necessidades especiais (Figura 3a), dentre estas necessidades o déficit de atenção e a deficiência física como os de maior ocorrência seguido pelo déficit intelectual e a Síndrome de Down (Figura 3b).

Figura 3 - Alunos com Necessidades Especiais (a) e qual Tipo Necessidade Especial (b) nas turmas em que ministrou aulas de Educação Física.

Revista Extensão em Foco, nº 19, Jul./ Dez. (2019), p. 11 - 32. 


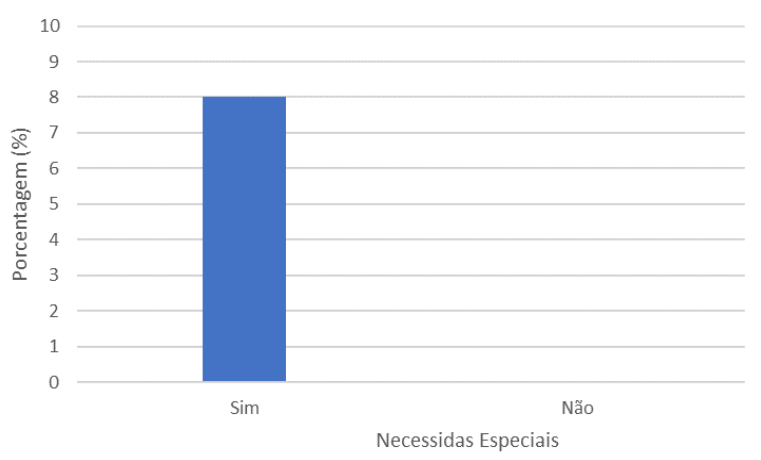

(a)

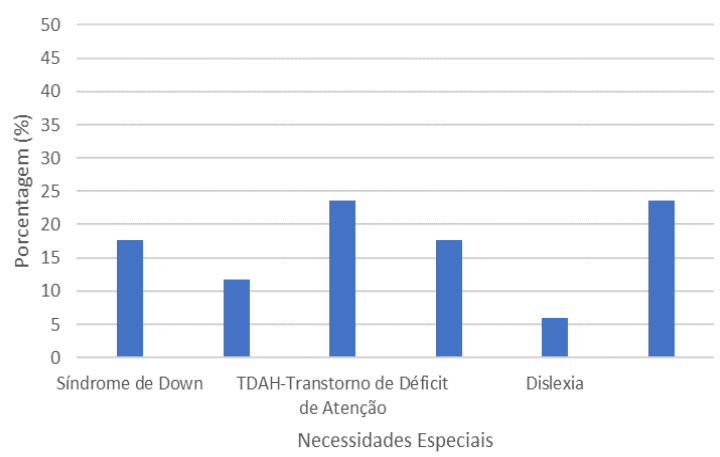

(b)

Na Figura 4 apresenta a relação de quando o profissional de licenciatura em Educação Física ministrou uma disciplina especificamente para estudantes com necessidades educativas (Figura 4a) e qual o tipo Necessidade Especial (Figura 4b).

Figura 4 - O profissional de licenciatura em Educação Física, ministrou uma disciplina especificamente para estudantes com Necessidades Educativas (a) e qual o Tipo Necessidade Especial (b).

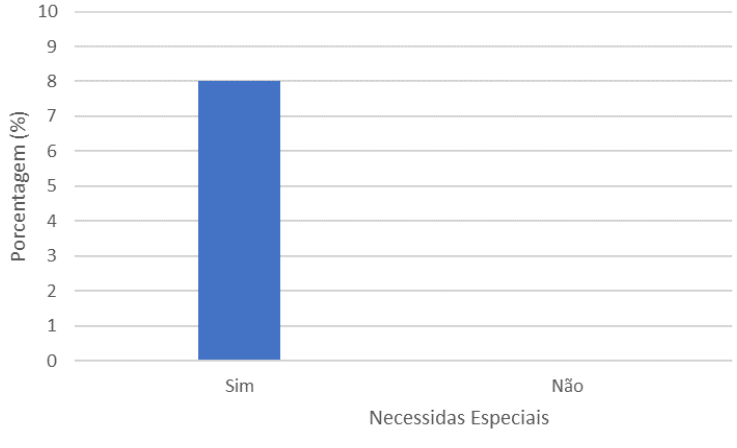

(a)

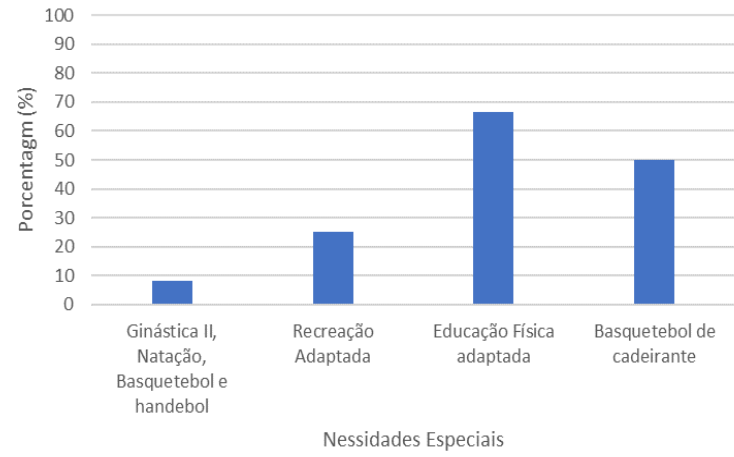

(b)

Todos os professores na sua formação tiveram em seu curso de formação docente alguma disciplina especifica para trabalhar com estudantes com necessidades educativas especiais. A Figura 5 apresenta se o profissional se sente preparado para trabalhar com estudantes com Síndrome de Down.

Figura 5- O profissional está preparado para trabalhar com estudantes com Síndrome de Down.

Revista Extensão em Foco, nº 19, Jul./ Dez. (2019), p. 11 - 32. 


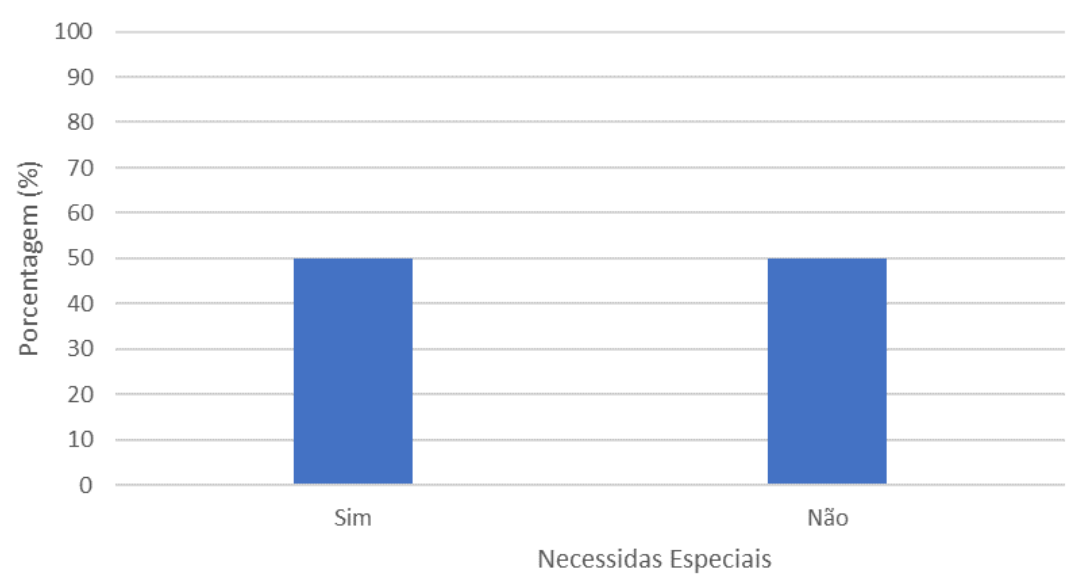

$\mathrm{Na}$ Tabela 1 descreve o motivo pelo profissional sentir - se preparado (a) e as preocupações ou cuidados (b) enfrentados por esse profissional em trabalhar com estudantes com Síndrome de Down.

Tabela 1 - motivo pelo profissional sentir - se preparado (a) e as preocupações ou cuidados (b) enfrentados por esse profissional em trabalhar com estudantes com Síndrome de

Down.

\section{Motivação}

(a)

(b)

\begin{tabular}{|c|c|c|}
\hline 1 & $\begin{array}{l}\text { Estas crianças precisam de uma atenção } \\
\text { especial devido ao seu problema, são } \\
\text { carinhosas e na maioria dão menos trabalho } \\
\text { que outras crianças. }\end{array}$ & $\begin{array}{l}\text { Respeito dos colegas, não ser tratado } \\
\text { diferente dos outros. }\end{array}$ \\
\hline 2 & $\begin{array}{l}\text { Ainda não tive a experiência diante deste fato, } \\
\text { mas acredito que passo conseguir } \\
\text { desempenhar bem o trabalho. }\end{array}$ & $\begin{array}{l}\text { Atenção, desafios, entendimento e } \\
\text { cuidado na hora da execução da } \\
\text { atividade, apesar de muitas poderem } \\
\text { surpreender. }\end{array}$ \\
\hline 3 & $\begin{array}{l}\text { Tenho formação e experiência para trabalhar } \\
\text { com alunos especiais. Procuro fazer cursos e } \\
\text { ler bastante sobre a inclusão - forma de } \\
\text { trabalhar com meu aluno junto com os demais } \\
\text { sem fazer diferença. Incluindo ele nas } \\
\text { atividades, respeitando suas limitações. }\end{array}$ & $\begin{array}{l}\text { Trazer atividades para trabalhar com } \\
\text { toda a turma onde seja possível incluí-la } \\
\text { nas mesmas, tentando sempre buscar o } \\
\text { melhor aproveitamento. }\end{array}$ \\
\hline
\end{tabular}

Revista Extensão em Foco, nº 19, Jul./ Dez. (2019), p. 11 - 32. 


\begin{tabular}{ll}
\hline $\begin{array}{l}\text { Devido aos cursos oferecidos na instituição } \\
\text { onde formei - me na graduação }\end{array}$ & $\begin{array}{l}\text { Desenvolvimento físico e procurar } \\
\text { incluir o mesmo com os demais. }\end{array}$ \\
\hline
\end{tabular}

Porque necessito de um estudo e

5 aperfeiçoamento, conhecimento ajuda no

A alimentação, os tipos de exercícios, preparo para o trabalho com estes alunos. aeróbicos ou anaeróbicos, etc.

6 Especializei-me nesta área

Primeiramente inclusão, em escolas públicas ainda não houve, segundo em uma escola privada houve participação efetiva das atividades.

7

Por não ter tido uma formação focada para portadores de necessidade.

Primeiramente se não há outras deficiências associadas, e de acordo com as possibilidades vou estimulando a participação do aluno e a resposta ele vai me dando de acordo com as aulas.

O conteúdo trabalhado nas universidades em Nós devemos ter um cuidado com todos relação a pessoas com necessidades especiais os alunos, porém estudantes com é bem superficial, não preparando o Síndrome de Down os cuidados são 8 profissional para a verdadeira realidade redobrados, pois apresentam algumas encontrada nas escolas. Então, cabe a ele limitações, mas devemos nos policiar buscar uma capacitação complementar para não excluir os demais e superproteger o lidar com possíveis situações. aluno.

Embora todos os entrevistados tenham afirmado que na sua formação acadêmica tiveram alguma disciplina especifica para trabalhar com esses tipos de alunos, $50 \%$ deles afirmaram que sente despreparado para atuar com esses alunos.

A partir das respostas dos professores entrevistados constata-se a fragilidade da formação docente para o atendimento das pessoas com necessidades educativas especiais. Mesmo com o discurso da inclusão educacional apresentado na mídia e nos cursos de formação docente ainda não acontece a formação docente do professor de Educação Física com bases conceituais, teóricas e práticas que permitam o exercício docente com segurança, de forma a atender as necessidades dos estudantes.

Revista Extensão em Foco, no 19, Jul./ Dez. (2019), p. 11 - 32. 
Nesta pesquisa também foi abordado sobre a preocupação ou cuidados dos professores com os portadores de síndrome. Muitos afirmaram que procura incluir os mesmos dentro do ambiente escolar e fazendo que todos participem das atividades. Percebe-se a preocupação com a escolha das atividades adequadas para cada caso e o cuidado para não esquecer os demais estudantes de forma que as atividades e metodologias de trabalho possam limitar o desenvolvimento dos demais. A Tabela 2 relaciona aos estudantes com Síndrome de Down atendidos em aulas estão possui padrões da normalidade quanto à composição corporal (a) e a forma de verificação (b).

Tabela 2 - Os estudantes com Síndrome de Down que são atendidos em aulas estão possui padrões da normalidade quanto à Composição Corporal (a) e a Verificação (b).

\begin{tabular}{|c|c|c|}
\hline & Padrões & Verificação \\
\hline & (a) & (b) \\
\hline 1 & $\begin{array}{l}\text { Em nossa escola não temos estes alunos } \\
\text { atualmente. }\end{array}$ & É feita pela relação altura e peso. \\
\hline 2 & Não respondeu & Através do IMC. \\
\hline 3 & $\begin{array}{l}\text { Sim. Foi sempre uma criança estimulada pela } \\
\text { família, isso é um fator que influencia muito no } \\
\text { desenvolvimento, é um menino ativo e não se } \\
\text { enquadra dentro de um grupo de obesidade. }\end{array}$ & $\begin{array}{l}\text { Observando seu comportamento na } \\
\text { realização das atividades propostas e } \\
\text { nos testes realizados a partir de dados } \\
\text { coletados. }\end{array}$ \\
\hline 4 & Sim & Utilizando o IMC. \\
\hline 5 & Não tenho nenhum & $\begin{array}{l}\text { A escola e a família deverão levar a } \\
\text { uma nutricionista trabalhando com } \\
\text { estes alunos (acompanhamento e } \\
\text { alimentação). }\end{array}$ \\
\hline 6 & $\begin{array}{l}\text { Quando tive, sim. São alunos absolutamente de } \\
\text { aparência e corpo normais. }\end{array}$ & Não especificou. \\
\hline 7 & $\begin{array}{l}\text { Tenho um aluno e ele é participativo, dentro de } \\
\text { suas limitações e não está acima do peso. }\end{array}$ & Através do IMC. \\
\hline
\end{tabular}

Revista Extensão em Foco, no 19, Jul./ Dez. (2019), p. 11 - 32. 


\begin{tabular}{llll}
\hline Não, pois devido à patologia os mesmos & Como educador físico utiliza o meio \\
8 apresentam algumas limitações físicas que & mais ágil e fácil de mensurar a \\
difere dos demais alunos. & & composição corporal, que é o IMC \\
\hline
\end{tabular}

A partir das respostas dos professores entrevistados percebe-se que os mesmos não evidenciaram ter atualmente estudantes com Síndrome de Down situados dentro dos quadros de obesidade na Tabela 2 (a). A Tabela 2 (b) apresenta a forma de detecção da composição corporal de seus estudantes, principalmente aqueles com Síndrome Down apresentam índices normais de composição corporal?

Praticamente todos os professores pesquisados foram unânimes na utilização do índice de Massa Corporal como referência para a observação da composição corporal dos seus estudantes. A Tabela 3 (a) demostra a em relação as aulas de Educação Física escolar podem auxiliar na prevenção da obesidade e seus quadros para os estudantes com Síndrome de Down e o planejamento das aulas você costuma prever atividades que possam prevenir a obesidade para os estudantes (b)

Tabela 3 - As aulas de Educação Física Escolar podem auxiliar na prevenção da obesidade e seus quadros para os estudantes com Síndrome de Down (a) e o planejamento das aulas você costuma prever atividades que possam prevenir a obesidade para os estudantes (b).

\section{Aulas}

(a)

1 Através das atividades físicas e segundo Sim primeiramente através dos dosando o ritmo delas. benefícios das atividades físicas e segundo dosando o ritmo delas.

2 Através dos movimentos psicomotores. Sim trabalho com natação e a mesma tem grande função na perda de peso e no ganho muscular.

3 Observando seu comportamento na realização $\operatorname{Sim}$ atividades que trabalhe das atividades propostas e nos testes realizados a partir de dados coletados. condicionamento físico força e resistência. Com aulas movimentadas onde permite o aluno gastar energias e buscar um melhor desenvolvimento.

Revista Extensão em Foco, no 19, Jul./ Dez. (2019), p. 11 - 32. 


\begin{tabular}{llll}
\hline 4 & Através das atividades recreativas & \\
& desenvolvida na instituição escolar, também & Recreação \\
& com devido de uma boa alimentação. & \\
\hline $\mathbf{5}$ & A escola e a família deverão levar a uma & Sim. Fazendo uma prevenção e \\
& nutricionista trabalhando com estes alunos & detectando os alunos obesos no início \\
& (acompanhamento e alimentação). & do ano letivo. \\
\hline
\end{tabular}

6 Nem sempre tem um corpo normal, a maioria das vezes, sedentários e obesos, uma pequena maioria tem muita vontade de participar das atividades, sem cobrança e sem resultado, Sempre, através de palestras, vídeos e fotos expostas. naturalmente.

\begin{tabular}{lll}
\hline $\mathbf{7}$ & Com atividades voltadas ludicamente & Sim de acordo com a proposta \\
& dependendo da faixa etária ou jogos etc. & $\begin{array}{l}\text { curricular é ofertado aos alunos } \\
\text { atividades que previnem ou amenizam }\end{array}$ \\
& & a obesidade, seguindo vários autores. \\
\hline $\mathbf{8}$ & Incluindo os mesmos na participação das & Sim, em todas as minhas aulas, pois \\
& atividades. & qualquer atividade física contribui para \\
& prevenção de obesidade.
\end{tabular}

A preocupação maior dos professores para a prevenção da obesidade é através do planejamento de atividades nas quais todos os estudantes participem e desta forma se beneficiem das atividades e exercícios. Entendem que estudantes se mantendo os mais ativos possíveis nas aulas queimarão mais energia e desta forma as aulas de Educação Física escolar possam contribuir na prevenção da obesidade.

Em relação a obesidade todos os professores afirmaram que no seu planejamento de aulas de Educação Física escolar utilizam atividades que ajudam a prevenir a obesidade. As atividades mencionadas não se destinam somente aos estudantes, mas também aos seus familiares, incluindo palestras, filmes e vídeos.

Segundo Nasha (2001) a Educação Física escolar deve servir de base educacional para uma vida funcional, utilizando crescentes e proporcionando o conhecimento dos conceitos em torno da aptidão física e da saúde, considerando que o indivíduo o levará o mesmo para o resto Revista Extensão em Foco, no 19, Jul./ Dez. (2019), p. 11 - 32. 
da vida. Sendo assim a escola necessita através de suas propostas pedagógicas, e professores e pedagogos utilizar estratégias relativas ao combate e a prevenção da obesidade, para que conscientizem acerca dos benefícios e necessidade dessa prática. precisam de cursos de aperfeiçoamento nessa área. E os que responderam sim, já tiveram experiência e são formados nesse campo.

\section{Índice de Massa Corporal - IMC dos Estudantes com Síndrome de Down}

Foi realizado a teste do Índice de Massa Corporal - IMC em 10 estudantes com Síndrome de Down, sendo 06 do sexo feminino e 04 do sexo masculino. Todos os estudantes frequentam a Escola de Educação Especial de Lucas do Rio Verde - MT. Entre os estudantes pesquisados percebe-se que maiorias que estão acima do peso são. Os alunos do sexo feminino foi o que causou mais espanto, pois 100\% dos entrevistados que estão no grupo da obesidade II e III, são mulheres. Todos estes estudantes participam das aulas de Educação Física escolar, conforme nos relatou a professora da escola na oportunidade da coleta destes dados. A Figura 6 apresenta a relação nutricional e do sexo dos participantes.

Figura 6 - Relação entre o estado nutricional e o sexo dos participantes.

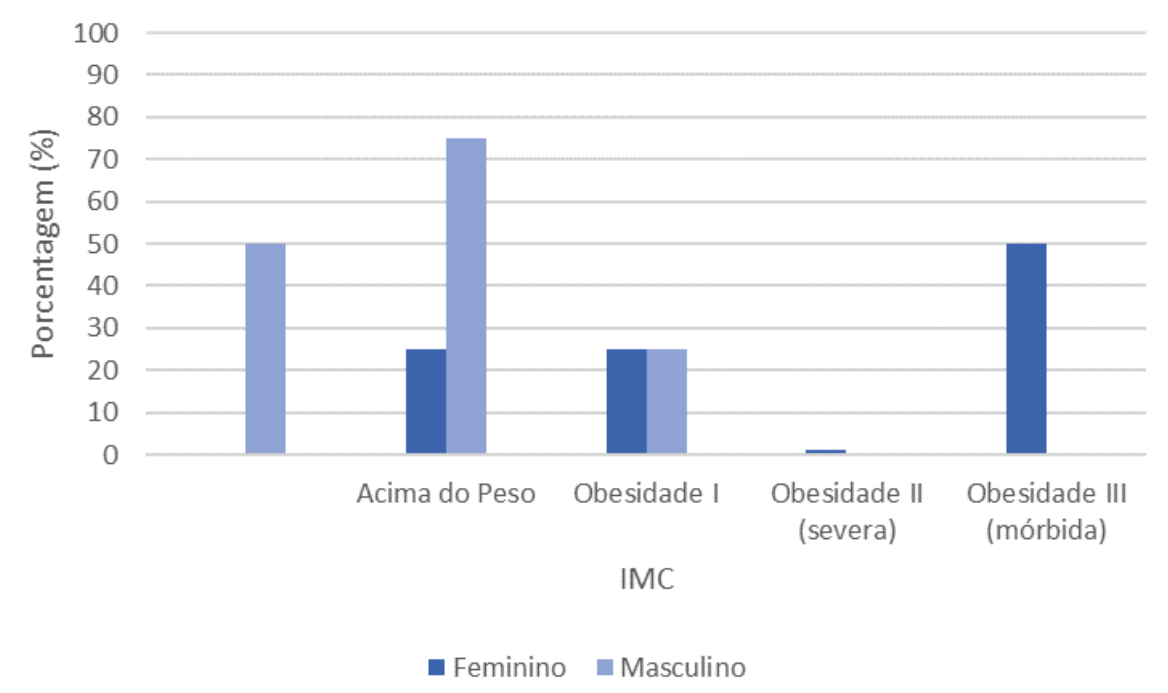

No Brasil, este fato entre crianças e adolescentes constitui uma grande preocupação entre os profissionais da área da saúde, uma vez que durante a infância e a adolescência aproximadamente dois entre 10 jovens obesos já são portadores da síndrome metabólica (FERREIRA, 2007). Com visão entre os portadores da Síndrome de Down tem essa Revista Extensão em Foco, no 19, Jul./ Dez. (2019), p. 11 - 32. 
preocupação em chegar a um estado metabólico e entre os entrevistados vemos uma grande inquietação com a em relação a obesidade, e com as condições as alimentares desses pesquisadores.

\section{Contribuições do Profissional da Nutrição}

Com relação à Síndrome de Down, sabe-se que os cromossomos contribuem para a obesidade. Assim, de acordo com os estudos nutricionais, há alguma indicação alimentar diferenciada? Em questão da pessoa que tem a síndrome de Down o grande cuidado que tem que ter em relação à alimentação são a questão dos alimentos mais gordurosos, que são os alimentos encontrados principalmente os fast food. Como eles já têm tendência maior a ter a obesidade, necessitam redobrar os cuidados com esses alimentos. O ideal mesmo pra eles é ter uma reeducação alimentar.

\section{CONSIDERAÇÕES FINAIS}

Com desenvolvimento desse estudo realizado na cidade de Lucas do Rio Verde - MT a partir do objetivo geral que intentou em saber se a Educação Física Escolar e a prevenção da obesidade nas pessoas com Síndrome de Down. Os resultados obtidos demonstraram que os estudantes apresentam uma propensão grande a desenvolver excesso de peso.

As dislipidemias podem ser explicadas pelo estilo de vida mais sedentário e pela alimentação incorreta, além dos fatores genéticos que alteram o metabolismo desses indivíduos. A detecção precoce do perfil lipídico em portadores de Síndrome de Down pode auxiliar na conduta clínica, propiciar uma intervenção nutricional e estilos de vida adequados.

$\mathrm{Na}$ pesquisa constatou que todos os professores já tiveram algum aluno com necessidades especiais. Embora contiveram na sua formação acadêmica disciplinas especifica para trabalhar com esses alunos, alguns professores sentem-se despreparado para atender esses alunos. Há uma preocupação dos profissionais da área da Educação Física em relação à inclusão dos portadores de necessidades especiais, dentro do ambiente escolar. Os planejamentos de aulas são elaborados com a necessidade de atender a todos, sem exclusão ou superproteção, atendendo sempre no limite de cada indivíduo. Através do planejamento de aula, os professores trabalham atividades e exercícios que possam ajudar na prevenção da obesidade.

Revista Extensão em Foco, no 19, Jul./ Dez. (2019), p. 11 - 32. 
Assim prevenir a obesidade no que se refere a atuações educativas na infância e na adolescência pode implicar na formação do procedimento que almeje hábitos e atitudes saudáveis. Nesse sentido a escola tem um papel importante no desenvolvimento de ações e aplicação de programas educacionais capazes de aperfeiçoar as condições da saúde e o estado nutricional dos educandos. Com propostas e concepção pedagógicas que solicitem atividades físicas regulares e a ampliação de hábitos saudáveis como a alimentação adequada à faixa etária infanto-juvenil e de forma interdisciplinar.

A partir dos dados obtidos consideramos que as aulas de Educação Física Escolar não se constituem enquanto prática de atividades físicas capazes de prevenir o desenvolvimento de variados graus de obesidade nos estudantes com Síndrome de Down.

\section{REFERÊNCIAS BIBLIOGRÁFICAS}

ABESSO, Associação Brasileira para o Estudo da Obesidade e da Síndrome Metabólica Obesidade Infantil. 15 Edição. Disponível em www.abeso.org.br. Acesso em maio de 2017.

ALVES-MAZZOTTI, A. J. Representações sociais: aspectos teóricos e aplicações à Educação. Brasília, 1994.

BETTI, M. Educação Física e sociedade. São Paulo, Movimento, 1991.

BEYER, H.O. Por que Lev Vygotski quando se propõe uma educação inclusiva? Revista Educação Especial, Santa Maria, n. 26, 2005. Disponível em www.coralx.ufsm.br. Acesso em maio de 2018.

CAMPANELli, J. R., DE SOUZA, A. B., DE SOUZA, J. X., GRILLO, D. E. Síndrome de Down: Conhecendo a percepção dos pais sobre a atuação de profissionais de educação física. Cadernos de Pós-Graduação em Distúrbios do Desenvolvimento, v. 14, p. 1, 2018.

CRONK, C., CROCKER, A.C., PUESCHEL, S.M., SHEA, A.M., ZACKAI, E., PICKENS, G. Growth charts for children with Down syndrome: 1 month to 18 years of age. Pediatrics v. 81, p. 102-110, 1988.

DA SILVA, L. O., DA SILVA LIMA, N., SANTOS, D. S., DA SILVA AFONSO, B., MATIELO, D., E. D. A, C., DA SILVA, A. C. A. A Formação de uma Professora de Educação Física com Síndrome de Down: Um Estudo de Caso. Biomotriz, v. 12, p. 2, 2018. DAOLIO, J. Educação Física e Conceito de Cultura. Autores Associados, Campinas, SP. 2004.

Revista Extensão em Foco, no 19, Jul./ Dez. (2019), p. 11 - 32. 
DARIDO, S.C. A Educação Física na escola e o processo de formação dos não participantes de atividade física. Revista Brasileira de Educação Física e Esportes. São Paulo, v. 18, n. 1, p. 61-80, 2004.

DIAS, I. R. Educação especial e educação inclusiva: teoria, pesquisa e prática. Perspectivas em Diálogo: Revista de Educação e Sociedade, v. 5, p. 282-283, 2018.

DUARTE, E., COSTA, L. T., GORLA, J. I. Síndrome de Down: crescimento, maturação e atividade física. Phorte Editora LTDA. 2017.

EDLER CARVALHO, R. Temas em: Educação Especial. Edição WVA, Rio de Janeiro, RS, 1998.

FIGUEIRA, E. O que é educação inclusiva. Brasiliense. 2017.

FERREIRA, A. P., OLIVEIRA, C. E. R., FRANÇA, N. M. Síndrome metabólica em crianças obesas e fatores de risco para doenças cardiovasculares de acordo com a resistência à insulina. J Pediatr, Rio Janeiro, 2007.

FREIRE, J. B. Educação de Corpo Inteiro, Teoria e Prática da Educação Física. Editora Scipione, São Paulo, SP, 1994.

GLAT, R. A integração social dos portadores de deficiências: uma reflexão. Editora Agir, Rio de Janeiro, RJ, 1995.

GOFFREDO, V. L. F. S. de. Integração ou segregação? O discurso e a prática das escolas públicas da rede oficial do município do Rio de Janeiro. 1998. Dissertação de Mestrado em Educação da Universidade do Estado do Rio de Janeiro, Rio de Janeiro. 1998.

LIMA, P.A. Educação inclusiva e igualdade social. Editora Avercamp, São Paulo, SP, 2006. MANTOAN, M. T. E. O direito de ser, sendo diferente, na escola in RODRIGUES, D. (organizador) Inclusão e Educação: doze olhares sobre a educação inclusiva. Editora Summus São Paulo, SP, 2006.

LOPES DE CARVALHO, C. e FERREIRA DE ARAÚJO, P. Inclusão escolar de alunos com deficiência: interface com os conteúdos da Educação Física. Educación Física y Ciencia, v. 20, 2018).

MRECH, L. M. Educação inclusiva: realidade ou utopia? Educação on-line, 2001. Disponível em www.educacaoonline.pro.br. Acesso em maio 2017.

NAHAS, M. Atividade física, saúde e qualidade de vida: conceitos e sugestões para um estilo de vida ativo. $2^{a}$ Edição, Editora Midiograf, Londrina, PR, 2001.

Revista Extensão em Foco, no 19, Jul./ Dez. (2019), p. 11 - 32. 
NEIRA, M.G. Educação Física: desenvolvendo competências. Editora Phorte, São Paulo, SP, 2003.

NUNES, M. D. F. Educação Inclusiva: Inclusão da criança com a Síndrome de Down na escola regular. Revista Eletrônica da Faculdade de Alta Floresta, v. 6, n. 2, 2017.

OTTO, P.G., OTTO, P.A., FROTA-PESSOA, O. Genética humana e clínica. $2^{\circ}$ Edição, Editora Roca, São Paulo, SP, 2004.

PANIAGUA, G. As famílias de crianças com necessidades educativas especiais. In: COLL, C., MARCHESI, Á., PALACIOS, J. Desenvolvimento psicológico e educação: transtornos de desenvolvimento e necessidades educativas especiais. $2^{\circ}$ Edição, Editora Artmed, Cap. 17, p. 330-346, Porto Alegre, RS, 2004.

PUESCHEL, S. Síndrome de Down: guia para pais e educadores. Tradução Lúcia Helena Relly PINHEIRO, Anelise Rízzolo de Oliveira et al. Uma Abordagem Epidemiológica da Obesidade. Campinas, 2004.

SANTOS, A.R. Metodologia científica: A construção do conhecimento. $7^{\circ}$ Edição, Editora Lamparina, Rio de Janeiro, RJ, 2005.

SCHWARTZMAN, J. S., TORRE, C. A., BRUNONI, D., SCHWARTZMAN, F., SCHWARTZMAN, M. L. C., VÍTOLO, M. R., MILLS, N. D., CASARIN, S., GUSMAN, S. Síndrome de Down. Editora Mackenzie, São Paulo, SP, 1999.

SASSAKI, R. K. Inclusão: Construindo uma sociedade para todos. 5. Edição, Editora WVA, Rio de Janeiro, RJ, 2003.

SILVA, E. L. da, MENEZES, E. M. Metodologia da pesquisa e elaboração de dissertação. 3. ed. Florianópolis: Laboratório de ensino a distância da Universidade Federal de Santa Catarina, 2001.

SILVA, J. C. A., SOUSA, F. D. C. A., SILVA, R. C. C. A importância da alimentação em pessoas com síndrome de Down-uma revisão. Revista Ciência \& Saberes-Facema, v, 3, n. 3, p. 636-641. 2017.

SILVA, K. C. D. Inclusão Social de Alunos com Deficiência nas Aulas de Educação Física. 2018.

TORRES GONZÁLEZ, J. A. Educação e diversidade: bases didáticas e organizativas. Editora Artmed, Porto Alegre, RS, 2002.

WILLIAMS, S. J., BENDELOW, G. The lived body - sociological themes, embodied issues. London: Routledge, 1998.

Revista Extensão em Foco, nº 19, Jul./ Dez. (2019), p. 11 - 32. 
Revista Extensão em Foco, no 19, Jul./ Dez. (2019), p. 11 - 32. 